\title{
Synthesis of Novel Polythiol for Plastic Optical Lens and its Ophthalmic Lens
}

\author{
Dong Gyu Jang, ${ }^{\dagger, \ddagger}$ Soo Gyun Roh, ${ }^{\ddagger}$ Jong Hyo Kim, ${ }^{\ddagger}$ Wen Yi Jin, ${ }^{\ddagger}$ Jin Moo Seo,${ }^{\ddagger}$ Myeong Ja Kwon, ${ }^{\dagger}$ and Soo Min Lee ${ }^{\dagger}{ }^{*}$ \\ ${ }^{\dagger}$ Deparment of Chemistry, College of Life Science and Nanotechnologv, Hannam Lniversity, Daejeon 305-811, Korea \\ ${ }^{*} E$-mail: smlee'ohannam.ackr \\ ${ }^{\ddagger}$ Optical Material Institute, Shin Dae Specialties Co., Lid., Daejeon 305-380, Korea \\ Received April 23, 2009. Accepted Alugust 9, 2009
}

\begin{abstract}
Novel poly thiol materials of urethane lens series for plastic optical lens were synthesized from polyol materials via thioisouronium of thiourea with $\mathrm{c}-\mathrm{HCl}$ in refluxing aqueous solution, in which polythiol material was carried out from hydrolysis of thioisouronium by ammonia water. Their structure properties were identified by EA, EI-MS. FT-IR, ${ }^{1} \mathrm{H}$ and ${ }^{13} \mathrm{C}$ NMR spectroscopies and TGA. Their oplthalmic lenses as polythiourethane material were prepared by themal curing to an injected glass mold using the evenly solutions of disocyanates series (TDI, XDI. HDI or IPDI) with polythiols. Polythiourethane shows that the strong stretching mode for $\mathrm{SH}$ group of polythiol disappeared in FT-IR spectra after thermosetting polymerization. Thermal deformation starting temperature of ophthalnic lenses was deternined by TMA. Ophthalnic lenses made from characteristic polythiol and disocyanate series have transparency, colorless and good impact strength, in which thermal resistance and impact strength of ophthalmic lenses were influenced by diisocyanate series. Physical properties of ophthalmic lens have contrast themal resistance with inpact strength. The property of thermal resistance and impact strength for respective ophthalmic lenses was examined by TMA and drop ball test.
\end{abstract}

Key Words: Plastic optical lens, Polythiol, Polythiourethane. Refractive index, Abbe`s number

\section{Introduction}

Polythiourethane has been considerably interesting due to excellent physical and optical properties of plastic optical lenses since polythiol has been firstly used as materials of ophthalmic lenses. ${ }^{1}$ in which poly thiourethane optical lenses have good properties such as easy casting. high thermal resistance. good light resistance. good transmittance. good transparency. good weather resistance and good tintability. It has also easy etching and coating in the process of manufacturing lens. Polythiourthane lens is a hyperbranched thermosetting polymer obtained by polymerization of the evenly mixed polythiol with diisocyanate. it was prepared by thermal curing after casting into glass mold using clear solutions mixed from monomer resin and isocyanate series in the presence of cataly'st. Refractive index of ophthalmic lenses was determined by sulfur contents including ophthalmic lens and also polythiol compounds can be more easily controlled a rate of polymerization in comparison with polyol compounds. Also, dissocyanates used in polythiourea material are known such as aryl. alkyl. cycloalkane and heterocyle diisocyanate series. In case of alkyl isocyanates. it decreases refractive index due to a low refractive index of itself. while in case of aryl disocyanates. it isn't changed almost for refractive index of plastic optical lenses due to a high refractive index of aryl groups. Refractive indexes of plastic lens materials in plastic lens industry were divided into low refractive index (nd or $\mathrm{nE}, 1.50$ ). middle refractive index (nd or $\mathrm{nE}, 1.56$ ). high refractive index (nd or $\mathrm{nE}, 1.60$ ), super high refractive index (nd or $\mathrm{nE} .167$ or more than 1.70) and functional materials (photochromic dyes and high impact strength materials). Plastic optical lens materials of middle refractive index are well-known as acryl and aryl series. while those of high refractive index are known as acryl and urethane series. Plastic optical lens materials of super high refractive index are polythiourethane materials having refractive index of 1.67 formed from a mixed solution of urethane series with diisocyanate series ${ }^{--5}$ and also ophthalmic lens materials in the range of $1.70-1.76$ as episulfide series bearing high sulfur content. ${ }^{\text {s? }}$ Super high refractive index of urethane series is not reached to more than 1.70 because of decrease for the refractive index of diisocyanates.

Even though polythiol has not been studied widely in optical lens industry it is necessary to develop novel plastic materials in order to overcome a patent infringement of a well-known GST ${ }^{5}$ (2.3-bis(2-mercaptoethylthio)-propane-1thiol). Otherw ise. GMT ${ }^{8}$ (2-(2-mercaptoethylthio)-propane1.3-dithiol) by comparison with GST was easily changed as a yellow color under heating condition at $70^{\circ} \mathrm{C}$ and it has a smaller molecular weight. We have investigated in the mecharism of polythiols and synthesized new model compounds through the new synthetic route having larger molecular weight than GST.

Herein. we will report two novel polythiols. GMMT (2-\{3(2-mercaptoethylthio)-2-[2-(2-mercaptoethy lthio)ethylthio] propylthio \}ethanethiol) (1) and GSTT (2-\{2.3-bis-(2-(2-mercapto-ethylthio)ethylthio)propylthio sethanethiol) (2) and its opthalnuc lenses, in which $\mathbf{1}$ and $\mathbf{2}$ are materials of urethane lens series having high refractive index and super high refractive index. 1 and $\mathbf{2}$ as optical lens materials of urethane lens series in ophthalmic lens were synthesized and identified their structures and properties by elemental analysis, EI-MS, TGA. FT-IR spectroscopy, ${ }^{1} \mathrm{H}$ and ${ }^{13} \mathrm{C}$ NMR spectroscopies. Their plastic optical lenses were prepared and its properties were investigated by TMA and drop ball test. These studies are necessary in order to obtain excellent ophthalmic lenses and also the substitution effect for an import of the whole quantity 
from advanced nations to domestic companies which are related to urethane optical lens materials for plastic optical lens.

\section{Experimental Section}

Materials. DBTC (dibutyltin diclloride), epichlorohydrin. HDI (hexamethylene diisocyanate), HMPB (2-(2'-hydroxy -5methylphenyl)-2H-benzotriazole), HTA (1-hydroxy-4-( $p$-toluidin)anthraquinone). IPDI (diisophorone diisocyanate) 2-mercaptoethanol. perinone dye, PNPP (polyoxy ethylene nonyl phenyl phosphate). TDI (tolylene-2.4-diisocyanate) thiourea and XDI (xylylene diisocyanate) are purchased as industrial reagents and used without purification. $\mathrm{HCl} . \mathrm{NaOH}$ and TEA (triethylamine) were used as reagent grade and solvents used without purification. Distilled water passed through the ion exchange resin after the first distillation and it used after metal ion removed. GMT ${ }^{8}$ and $\mathrm{GST}^{5}$ were synthesized by a similar method as reported.

General procedure. Elemental analyses were carried out by EA1110 (CE Instrument, Italy), EI-MS data were obtained with JMS-AX505 WA (Jeol. Japan). FT-IR spectra were recorded on Perkin-Elmer Spectrum 1000 as KBr pellet. TGA (themogravimeteric analyzer) was recorded with thermal property with $\mathrm{Du}$ pont 990 Model $951 \mathrm{TGA}$ as $10^{\circ} \mathrm{C} / \mathrm{min}$ under air condition. ${ }^{l} \mathrm{H}$ and ${ }^{13} \mathrm{C}$ NMR spectra were recorded with Varian Oxford $300 \mathrm{MHz}$ spectrometer and the chemical shifts were reported in ppm units with tetramethylsilane (TMS) as an internal standard. TMA (thermomechanical analy sis) was performed with TMA Q 400 (TA instruments, USA) as $5{ }^{\circ} \mathrm{C} / \mathrm{min}$ under high pure nitrogen gas in order to obtain data of thermal expansion coefficient and thermal resistance. GC (Gas Chromatography) Analysis was performed on M660D (YoungLin. Korea) as column HP-1 ( $\&$ W Scientific) and heating condition of $20^{\circ} \mathrm{C} / \mathrm{min}$ in the range of $60-260^{\circ} \mathrm{C}$. HPLC analysis was measured on LC $20 \mathrm{~A}$ (Shimazhu. Japan) as C 18 reverse column (Ace $5.250 \times 4.6 \mathrm{~mm}$. ACE-128-2548. particle size 5 mm). a mixed solvent $\left(\mathrm{CH}_{3} \mathrm{CN}: \mathrm{H}_{2} \mathrm{O}=7: 3\right)$ and flow rate of $1 \mathrm{~mL} / \mathrm{min}$. Wavelength of UV detector was measured at 210 num. oven temperature measured at $40^{\circ} \mathrm{C}$. Refractive index and Abbe number data were performed with IT Abbe refractometer (ATAKO. Japan). Impact strength data were obtained by drop ball test of $95.1155 \mathrm{~g}$ (steel ball diameter $30 \mathrm{~mm}$ ) from a height of $170 \mathrm{~cm}$ with non-coated ophthalmic lenses having central lens thickness of 1.20.1.27 and 2.34 mm (impact resistance of lenses in FDA should be passed $16 \mathrm{~g}$ drop ball (diameter $15.9 \mathrm{~mm}$ ) test from a height of not less than $127 \mathrm{~cm}$ and it should be remained an intact without a crack and a damage)

Synthesis of 2-\{3-(2-mercapto-ethylthio)-2-[2-(2-mercaptoethylthio)-ethylthio]propylthio' ethanethiol (GMTT) (1). To $\mathrm{GMT}^{8}(186.85 \mathrm{~g}, 0.932 \mathrm{~mol})$ was added dropwise $25 \%$ aqueous $\mathrm{NaOH}$ solution $(447.52 \mathrm{~g} .2 .797 \mathrm{~mol})$ below $40^{\circ} \mathrm{C}$. Reaction temperature does not rise above $45^{\circ} \mathrm{C}$ in the process of reaction during addition of $25 \%$ aqueous $\mathrm{NaOH}$ solution. After stirring a reaction solution for 1 hour at $45^{\circ} \mathrm{C}, 2$-chloroethanol $(225.10 \mathrm{~g} .2 .797 \mathrm{~mol})$ was added to a suspension solution at $45^{\circ} \mathrm{C}$ and it was cooled with an ice bath due to a temperature raise during addition of 2-clloroethanol. After stirring for 2 hours at $45^{\circ} \mathrm{C}$. to this resulting polyol solution was added thiourea $(255.49 \mathrm{~g} .3 .356 \mathrm{~mol})$ and $\mathrm{c}-\mathrm{HCl}(364.48 \mathrm{~g} .4 .196$ mol) at about $30^{\circ} \mathrm{C}$. After refluxing at $110^{\circ} \mathrm{C}$ for 3.5 hours, it was cooled to room temperature. To this resulting solution was added dropwise $25 \%$ ammonia water $(370.87 \mathrm{~g}, 5.454$ mol) below $30^{\circ} \mathrm{C}$ and then toluene $(400 \mathrm{~mL}$ ). This suspension solution was hydrolyzed at $80^{\circ} \mathrm{C}$ for 1.5 hours and cooled up to roon temperature. The organic layer was separated, washed with $\mathrm{c}-\mathrm{HCl}(100 \mathrm{~mL})$ two times. and washed with $\mathrm{H}_{2} \mathrm{O}(100$ $\mathrm{mL}$ ) two times. The separated organic layer was evaporated under reduced pressure and completely removed solvent under vacuun to give a colorless liquid compound. 'H NMR $\left(\mathrm{CDCl}_{3}, 300 \mathrm{MHz}\right) \delta$ o 2.87-2.90 (m. 7H. $-\mathrm{CH}-\mathrm{HCH}_{2} \mathrm{CH}_{2} \mathrm{SH}$ ). $2.68-2.82$ (m. 14H, $-\mathrm{CH}-\mathrm{CH}_{2}-\mathrm{SCH}_{2} \mathrm{CH}_{2} \mathrm{H},-\mathrm{SCH}_{2} \mathrm{CH}_{2} \mathrm{SH}$, $-\mathrm{SCH}_{2} \mathrm{CH} \mathrm{H}_{2} \mathrm{~S}-$ ). $1.70-1.75$ (n. $3 \mathrm{H} .-\mathrm{CH}_{2} \mathrm{CH}_{2} \mathrm{SH}$ ). ${ }^{12} \mathrm{C}$ NMR $\left(\mathrm{CDCl}_{2}, 300 \mathrm{MHz}\right)$ oे $46.19(-\mathrm{CH}-), 36.88\left(-\mathrm{CH}_{2} \mathrm{CH}_{2} \mathrm{SCH}_{2}\right.$ $\mathrm{CH}-) .36 .38\left(-\mathrm{CH}-\mathrm{CH}_{2} \mathrm{SC} \mathrm{H}_{2} \mathrm{CH}_{2} \mathrm{SH}\right) .36 .03\left(-\mathrm{SCH}_{2} \mathrm{CH}_{2} \mathrm{SCH}_{2}\right.$ $\left.\mathrm{CH}_{2} \mathrm{SH}\right) .31 .97\left(-\mathrm{SCH}_{2} \mathrm{CH}_{2} \mathrm{SCH}_{2} \mathrm{CH}_{2} \mathrm{SH}\right) .31 .52\left(-\mathrm{SCH}_{2} \mathrm{CH}_{2}\right.$ $\left.\mathrm{SCH}_{2} \mathrm{CH}_{2} \mathrm{SH}\right), 24.71\left(-\mathrm{SCH}_{2}\left(\mathrm{CH}_{2} \mathrm{SH}\right)\right.$. FT-IR (KBr pellet. $\left.\mathrm{cm}^{-1}\right)$ : 2539 (thiol. SH). EI-MS [M ]: Calcd. (380.76), Found (380). Elemental Analysis: $\mathrm{C}_{11} \mathrm{H}_{24} \mathrm{~S}_{2}$ Calcd. (\%): C. 34.70: $\mathrm{H}, 6.35$ : S. 58.95. Exp. (\%) C. 34.55; H. 6.88; S, 58.58. Refractive index (nd at $20^{\circ} \mathrm{C}$ ): $1.6+42$.

Synthesis of (2-\{2,3-bis-(2-(2-mercapto-ethylthio)-ethylthio)propylthio ethanethiol) (GSTT) (2). GSTT was prepared by a similar synthetic procedure of GMTT. To GST ${ }^{5}$ (172.67 g. 0.663 mol) was added dropwise $25 \%$ aqueous $\mathrm{NaOH}$ solution (318.13 g. $1.988 \mathrm{~mol}$ ) below $40^{\circ} \mathrm{C}$. Reaction temperature does not rise above $45^{\circ} \mathrm{C}$ when addition of $25 \%$ aqueous $\mathrm{NaOH}$ solution. After stirring a reaction solution for 2 hours at $45^{\circ} \mathrm{C}$. 2 -chloroethanol ( $160.21 \mathrm{~g} .1 .990 \mathrm{~mol})$ was added to a suspension solution at $45^{\circ} \mathrm{C}$ and it was cooled with an ice bath due to a temperature raise during addition of 2-chloroethanol. To this polyol solution was added thiourea ( $181.61 \mathrm{~g}, 2.386 \mathrm{~mol}$ ) and $\mathrm{C}-\mathrm{HCl}$ (259.00 g. $2.982 \mathrm{~mol})$ and refluxed at $110^{\circ} \mathrm{C}$ for 3.5 hours. After this resulting solution was cooled to room temperature and then added dropwise ammonia water $(267.00 \mathrm{~g}$. $3.970 \mathrm{~mol}$ ) below $30^{\circ} \mathrm{C}$ and toluene $(250 \mathrm{~mL})$. This suspension solution was hydrolyzed at $80^{\circ} \mathrm{C}$ for 1.5 hours and it was cooled up to room temperature. The organic layer was separated. washed with $\mathrm{c}-\mathrm{HCl}(120 \mathrm{~mL})$ two times, and washed with $\mathrm{H}_{2} \mathrm{O}(120 \mathrm{~mL})$ two times. The separated organic layer was evaporated under reduced pressure and completely removed solvent under vacuun to give a colorless liquid compound. ${ }^{1} \mathrm{H}$ $\mathrm{NMR}\left(\mathrm{CDCl}_{2}, 300 \mathrm{MHz}\right)$ ò 2.85-2.99 (m. 7H, $-\mathrm{CH}-,-\mathrm{SCH}_{2}$ $\mathrm{CH}_{2} \mathrm{SH}$ ). 2.70-2.84 (n., 18H. -CH-CH$-\mathrm{SCH}_{2} \mathrm{CH}_{2} \mathrm{H}_{3}-\mathrm{SCH}_{2} \mathrm{CH}_{2}$ $\left.\mathrm{SH},-\mathrm{SCH} \mathrm{CH}_{2} \mathrm{~S}-\right), 1.74-1.79\left(\mathrm{~m}, 3 \mathrm{H}_{+}-\mathrm{CH}_{2} \mathrm{CH}_{2} \mathrm{SH}\right){ }^{15} \mathrm{C} \mathrm{NMR}$ $\left(\mathrm{CDCl}_{3} .300 \mathrm{MHz}\right)$ ô 46.11 (-(H-). $36.76\left(-\mathrm{SCH} \mathrm{CHCH}_{2} \mathrm{~S}-\right)$, $36.42\left(-\mathrm{SCH}_{2} \mathrm{CH}-\mathrm{CH} \mathrm{H}_{2} \mathrm{~S}-\right) .36 .26\left(-\mathrm{CH}-\mathrm{CH}_{2} \mathrm{SCH}_{2} \mathrm{CH}_{2} \mathrm{SH}\right), 35.91$ (- $\left.\mathrm{CHCH}_{2} \mathrm{SCH}_{2} \mathrm{CH}_{2} \mathrm{SH}\right) .35 .85\left(-\mathrm{SCH}_{2} \mathrm{CH}_{2} \mathrm{SCH}_{2} \mathrm{CH}_{2} \mathrm{SH}\right) .36 .26$ $\left(-\mathrm{SCH}_{2} \mathrm{CH}_{2} \mathrm{~S} \mathrm{CH}_{2} \mathrm{CH}_{2} \mathrm{SH}\right) 32.90\left(-\mathrm{SCH}_{2} \mathrm{CH}_{2} \mathrm{~S}-\mathrm{CH}_{2} \mathrm{CH}_{2} \mathrm{SH}\right)$, $31.87\left(-\mathrm{SCH}_{2} \mathrm{CH}_{2} \mathrm{~S} \mathrm{CH}_{2} \mathrm{CH}_{2} \mathrm{SH}\right), 31.77\left(-\mathrm{CH}_{-} \mathrm{CH}_{2} \mathrm{SCH}_{2} \mathrm{CH}_{2}\right.$ $\left.\mathrm{SCH}_{2} \mathrm{CH}_{2} \mathrm{SH}\right) .31 .42\left(-\mathrm{CH}-\mathrm{SCH}_{2} \mathrm{CH}_{2} \mathrm{SCH}_{2} \mathrm{CH}_{2} \mathrm{SH}\right), 24.71$ (-SCH $\mathrm{CH}_{2} \mathrm{SH}$ ). FT-IR (KBr pellet, $\mathrm{cm}^{-1}$ ): 2540 (thiol, SH). EI-MS [M']: Calcd (440.89). Found (440). Elemental Analy sis: $\mathrm{C}_{13} \mathrm{H}_{28} \mathrm{~S}_{8}$. Calcd. (\%): C, 35.41: H, 6.40: S, 58.18. Exp. (\%): C, $35.23: \mathrm{H}, 6.71$ : S. 58.33 . Refractive index (nd at $20^{\circ} \mathrm{C}$ ): 1.6405 . 
Ophthalmic lens of 1 with TDI (3). To suction flask was added TDI $(39.29 \mathrm{~g})$. DBTC $(0.08 \mathrm{~g})$ and PNPP $(0.10 \mathrm{~g})$. After evenly mixing a mixture. $1(60.71 \mathrm{~g})$ was added to reaction vessel. After removing gas under vacuum for 30 minutes, it injected into a glass mold and had a thermosetting polymerization. The resulting plastic lens had colorless and strong impact strength. Refractive index (nd at $20^{\circ} \mathrm{C}$ ) was 1.6589. Abbe's number 27.9 and thermal deformation starting temperature (Ts) $86.39^{\circ} \mathrm{C}$

Ophthalmic lens of 1 with XDI (4). To suction flask was added XDI ( $41.15 \mathrm{~g})$. DBTC $(0.08 \mathrm{~g})$ and PNPP $(0.10 \mathrm{~g})$. After evenly mixing a mixture. 1 (58.85 g) was added to reaction vessel. After removing gas under vacuum for 30 minutes, it injected into a glass mold and has a thermosetting polymerization. The resulting plastic lens had thin yellow color and strong impact strength. Refractive index (nd at $20^{\circ} \mathrm{C}$ ) was 1.6590 . Abbe's number 27.9 and thermal deformation starting temperature (Ts) $48.71^{\circ} \mathrm{C}$.

Ophthalmic lens of 1 with TDI, HDI and IPDI (5). To suction flask was added TDI (22.06 g), HDI (8.01 g). IPDI $(8.01 \mathrm{~g})$. HMPB $(1.20 \mathrm{~g})$. HTA $(0.176 \mathrm{~g})$, perinone dye $(0.12$ g). DBTC $(0.08 \mathrm{~g})$ and PNPP $(0.10 \mathrm{~g})$. After evenly mixing a mixture. $1(61.92 \mathrm{~g})$ were added to reaction vessel. After removing gas under vacuum for 30 minutes. it injected into a glass mold and cured. The resulting plastic lens had colorless and strong impact strength. Refractive index (nd at $20^{\circ} \mathrm{C}$ ) was 1.6585. Abbe's number 27.9 and thermal deformation starting temperature (Ts) $83.32^{\circ} \mathrm{C}$.

Ophthalmic lens of 1 with PETMP, HDI and IPDI (6). To suction flask was added HDI $(11.04 \mathrm{~g})$. IPDI $(34.03 \mathrm{~g})$. HMPB $(1.50 \mathrm{~g})$. HTA $(0.08 \mathrm{~g})$. DBTC $(0.08 \mathrm{~g})$ and PNPP $(0.10$ g). After evenly mixing a mixture, $1(40.24 \mathrm{~g})$ and PETMP $(14.69 \mathrm{~g})$ were added to reaction vessel. After removing gas under vacuum for 30 minutes. it injected into a glass mold and had a thermosetting poly merization. The resulting plastic lens had colorless and strong impact strength. Refractive index (nd at $20^{\circ} \mathrm{C}$ ) was 1.6041 , Abbe's number 40.32 and thermal deformation starting temperature (Ts) $52.47^{\circ} \mathrm{C}$.

The other ophthalmic lenses were prepared according to a similar procedure described above.

Ophthalmic lens of $\mathbf{2}$ with TDI (7). To suction flask was added TDI $(35.86 \mathrm{~g})$. DBTC $(0.08 \mathrm{~g})$ and PNPP $(0.10 \mathrm{~g})$. After evenly mixing a mixture. $2(64.14 \mathrm{~g})$ was added to reaction vessel. After removing gas under vacuum for 30 minutes, it injected into a glass mold and had a thermosetting polymerization. The resulting plastic lens had colorless and strong impact strength. Refractive index (nd at $20^{\circ} \mathrm{C}$ ) was 1.6586 . Abbe's number 27.9 and thermal deformation starting temperature (Ts) $69.92^{\circ} \mathrm{C}$.

Ophthalmic lens of $\mathbf{2}$ with XDI (8). To suction flask was added XDI (37.66 g). DBTC $(0.08 \mathrm{~g})$ and PNPP $(0.10 \mathrm{~g})$. After evenly mixing a mixture. $2(62.34 \mathrm{~g})$ was added to reaction vessel. After removing gas under vacuum for 30 minutes. it injected into a glass mold and had a thermosetting polymerization. The resulting plastic lens had thin yellow color and high impact strength. Refractive index (nd at $20^{\circ} \mathrm{C}$ ) was 1.6586. Abbe's number 27.9 and thermal deformation starting temperature (Ts) $40.65^{\circ} \mathrm{C}$
Ophthalmic lens of $\mathbf{2}$ with TDI, HDI and IPDI (9). To suction flask was added TDI $(20.09 \mathrm{~g})$. HDI $(7.30 \mathrm{~g})$. IPDI $(7.30 \mathrm{~g})$. $\mathrm{HMPB}(1.20 \mathrm{~g})$. $\mathrm{HTA}(0.176 \mathrm{~g})$. perinone dye $(0.12 \mathrm{~g})$. DBTC $(0.08 \mathrm{~g})$ and PNPP $(0.10 \mathrm{~g})$. After evenly mixing a mixture, $2(65.32 \mathrm{~g})$ was added to reaction vessel. After removing gas under vacuum for 30 minutes, it injected into a glass mold and had a thermosetting polymerization. The resulting plastic lens had colorless and high impact strength. Refractive index (nd at $20^{\circ} \mathrm{C}$ ) was 1.6581 , Abbe's number 27.9 and thermal deformation starting temperature (Ts) $67.67^{\circ} \mathrm{C}$.

Ophthalmic lens of 2 with PETMP, HDI and IPDI (10). To suction flask was added HDI (10.38 g). IPDI (31.99 g). HMPB $(1.50 \mathrm{~g})$. HTA $(0.08 \mathrm{~g})$, catalyst $(0.08 \mathrm{~g})$ and PNPP $(0.10 \mathrm{~g})$. After evenly mixing a mixture. $2(43.82 \mathrm{~g})$ and PETMP (13.81 g) were added to reaction vessel. After removing gas under vacuum for 30 minutes. it injected into a glass mold and had a thermosetting polymerization. The resulting plastic lens had colorless and ligh impact strength. Refractive index (nd at 20 $\left.{ }^{\circ} \mathrm{C}\right)$ was 1.594 . Abbe's number 40.55 and thermal deformation starting temperature (Ts) $50.66^{\circ} \mathrm{C}$.

\section{Results and discussion}

Synthesis and analysis of thiol matelials for plastic optical lens. Plastic optical lens of urethane lens series made using polythiol was produced firstly at Mitsui Toatsu Chemicals. Inc. ' they are world-wide top class for the production of thiol materials for plastic urethane optical lens. In general, polythiol materials were synthesized by conversion of $\mathrm{OH}$ group into $\mathrm{SH}$ group. Compound including $\mathrm{OH}$ group can be converted into $\mathrm{SH}$ group via the reaction of $\mathrm{SOCl}_{2}$ with thiourea or $\mathrm{HBr}$ with thiourea. ${ }^{[i,-12}$ In recent, it was synthesized by hydroly sis of $\mathrm{KOH}$ or anmonia water in refluxing base conditions via isothiouronium made using $\mathrm{HCl}$ and thiourea. ${ }^{13-14}$ In this work, thiol materials were prepared by hydrolysis of ammonia via isothiouronium obtained using $\mathrm{HCl}$ and thiourea as shown in Scheme 1 and $2 .^{15}$ We have tried to obtain thiol compounds using terminal groups such as 3-mercaptopropanol. propanol. ethanol or glycol except the existence of terminal 2-mercaptoethanol units but thiol materials were not produced without terminal 2-mercaptoethanol group. Thiol materials were completed through an intermediate existence of three member ring bearing $S$ atom and then formation and hydroly'sis of isothiouronium chloride as shown in Scheme 3.

1 and 2 were in accord with the estimated contents and molecular weight from elemental analysis and EI-MS. respec-

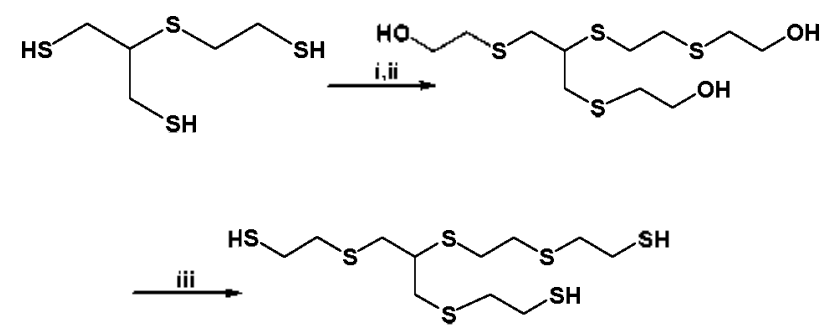

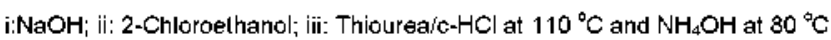

Scheme 1. Synthetic route of 1. 
<smiles>CC#CCCOCCSCC(CSCCSCCO)SCCSCCO</smiles><smiles>CC#CC</smiles>

i: $\mathrm{NaOH}$; ii: 2-Chloroelhanol; iii: Thiourea/C-HCl al $110^{\circ} \mathrm{C}$ and $\mathrm{NH}_{4} \mathrm{OH}$ al $80^{\circ} \mathrm{C}$

Scheme 2. Synthetic route of 2.
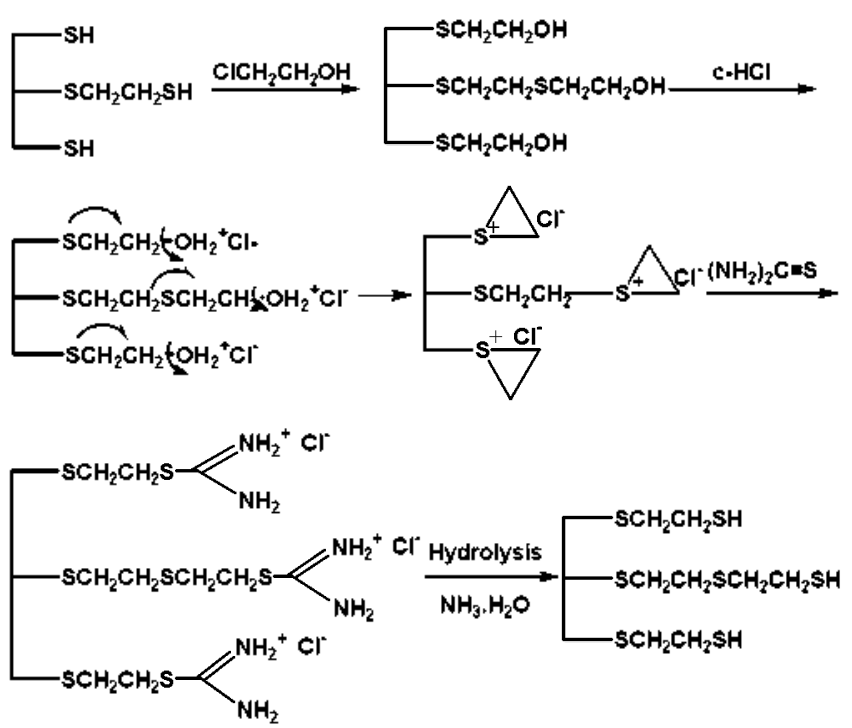

Scheme 3. Mechanism for synthetic route of 1.

tively: The thermal stability of $\mathbf{1}$ and $\mathbf{2}$ were more stable than that of GMT and GST in TGA thermograms as shown in Figurel. GMT was very unstable as thermal property and easily decomposed. while $\mathbf{1}$ is more stable in comparison with GST and 2. All compounds are stable up to $150{ }^{\circ} \mathrm{C}$ except GMT, these results can be estimated for thermal property of thiol materials as the order of GMT $<$ GST $<2<1$.

Analysis of ${ }^{1} \mathrm{H}$ NMR data for 1 and 2 indicated approximately three groups such as $-\mathrm{CH}$ - or $-\mathrm{SCH}_{2} \mathrm{CH}_{2} \mathrm{SH}$ at $2.85-3.00 \mathrm{ppm}$. $-\mathrm{CHCH}_{2} \mathrm{SCH}_{2} \mathrm{CH}_{2} \mathrm{SH}_{3}-\mathrm{SCH}_{2} \mathrm{CH}_{2} \mathrm{SH},-\mathrm{SCH}_{2} \mathrm{CH}_{2} \mathrm{~S}-$ at 2.70 $2.84 \mathrm{ppm}$ and $-\mathrm{CH}_{2} \mathrm{CH}_{2} \mathrm{SH}$ at $1.78 \mathrm{ppm}$. even though their assignments were not exactly determined due to a complicated peaks for similar conditions of polythiols. Analysis of ${ }^{13} \mathrm{C}$ NMR data for 1 and 2 indicated that the characteristic peak of $-\mathrm{CH}$ - showed one peak at $+6.19 \mathrm{ppm}$ for 1 and +6.11 ppm for 2. respectively, while that of terminal $-\mathrm{SCH}_{2} \mathrm{CH}_{2} \mathrm{SH}$ groups showed an equal peak at $24.71 \mathrm{ppm}$ for 1 and 2 .

Poperties of ophthalmic lenses. Ophthalmic lenses were prepared by thermal curing after casting into glass mold using well mixed solutions of thiol materials with diisocyanates in the presence of catalyst. 3 formed from the evenly mixed solutions of 1 with TDI shows that refractive index is 1.6591 and a Abbe's number 27.9, while 4 made from 1 with XDI has refractive index of 1.6590 and Abbe's number of 27.9.7 prepared from 2 with TDI has refractive index of 1.6586 and Abbe's mumber of 27.9. while 8 made from $\mathbf{2}$ with XDI has refractive index of 1.6588 and Abbe's number of 27 . However.

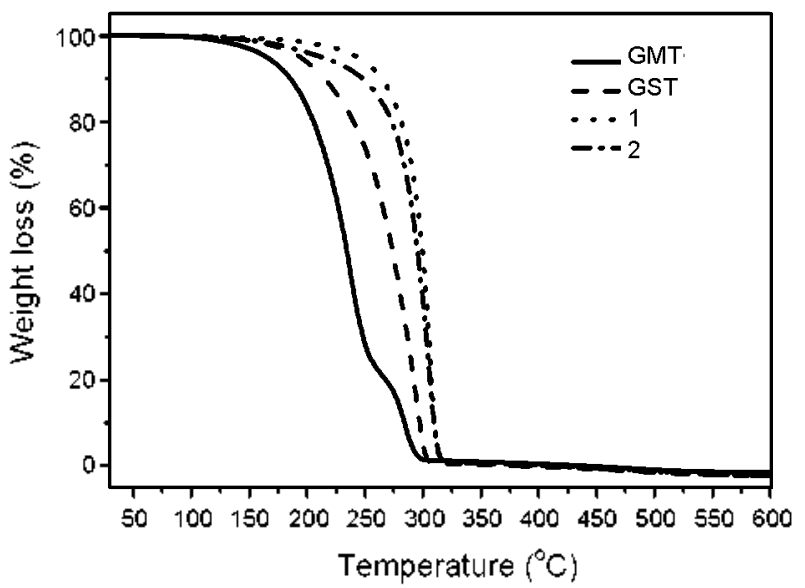

Figure 1. TGA themograms of GMT, GST, 1 and 2.

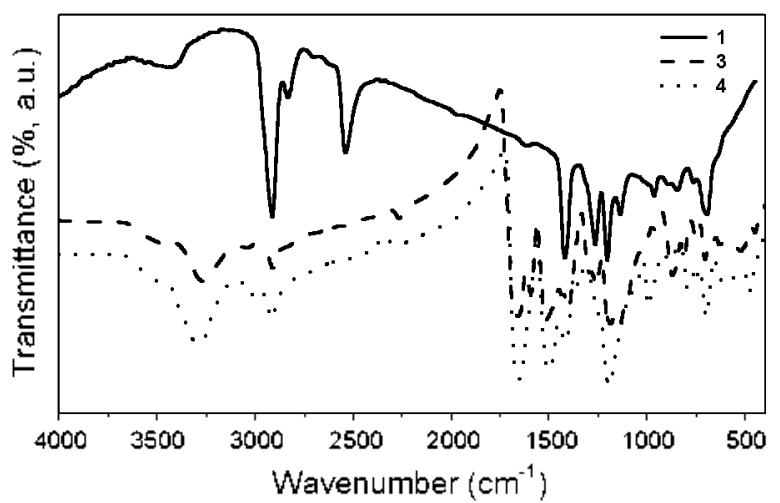

Figure 2. FT-IR spectra of 1,3 and 4 .

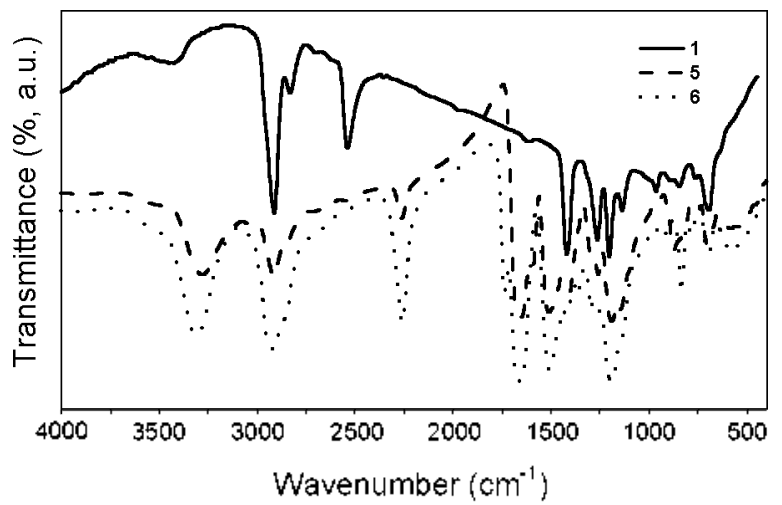

Figure 3. FT-IR spectra of 1,5 and 6 .

the preparation of optical lenses from the mixed solutions of 1 with IPDI and of 2 with IPDI. respectively. was not carried out successfully because they were mixed and poly merized each other. The preparation of ophthalmic lenses 5 and 6 by the improved methods of 1 with TDI. HDI and IPDI and 1 with PETMP. HDI and IPDI was carried out successfully. 5 made using the evenly mixed solutions of 1 with TDI. HDI and IPDI has super high refractive index of 1.6585 and Abbe's number of 27.9 and 6 made by 1 with PETMP. HDI and IPDI has high refractive index of 1.6041 and Abbe's number of 40.32 . Data of ophthalmic lenses 9 and $\mathbf{1 0}$ made from 2 by the same procedure of 1 have listed in experimental section. 
Figure 2 and 3 showed FT-R spectra of ophthalmic lenses 3 and 4 carried out by 1 with disocyanates. SH groups of polythiols in FT-IR spectra as shown in Fig. 2 and 3 are assigned to a strong stretching mode of $\mathrm{SH}$ in the region of $2539 \mathrm{~cm}^{-1}$ for 1 and that of $25+5 \mathrm{~cm}^{-1}$ for 2. respectively. ${ }^{15.16}$

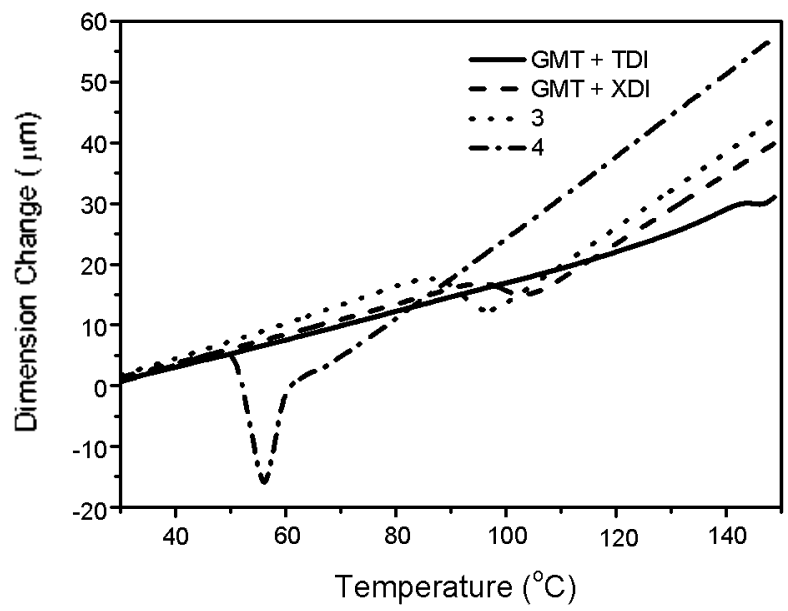

Figure 4. TMA curves of GMT+TDI, GMT+XDI, 3 and 4.

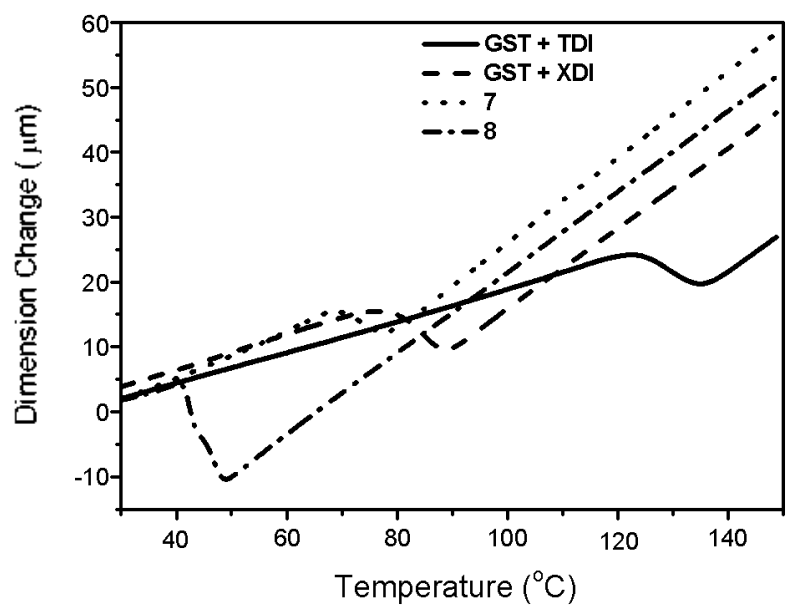

Figure 5. TMA curves of GST+TDI, GST+XDI, 7 and 8

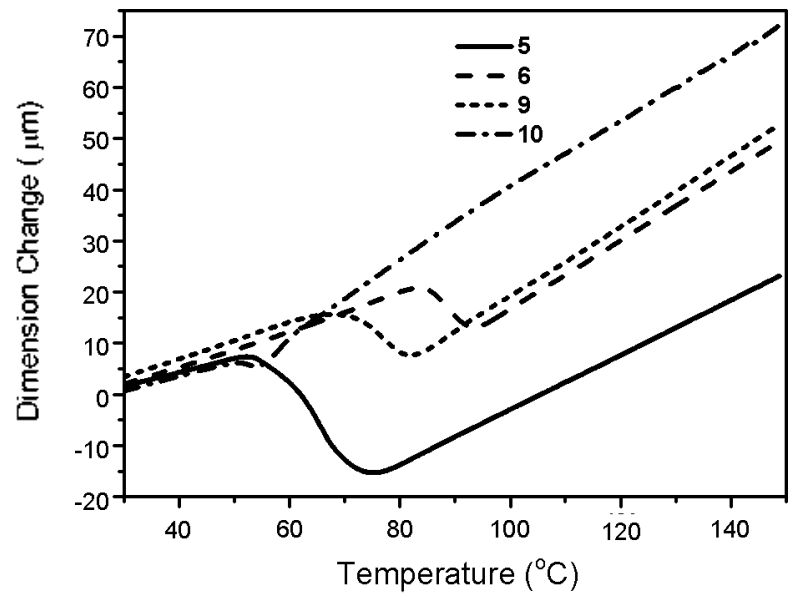

Figure 6. TMA curves of $5,6,9$ and 10 .
The strong stretching mode of SH groups for plastic optical lenses after polymerization of $\mathbf{1}$ with diisocyanates disappeared in FT-IR spectra. while stretching modes of $\mathrm{NH}$ and $\mathrm{C}=\mathrm{O}$ bonds appeared newly in FT-IR spectra as shown in Figure 2 and 3 . These results can confirm the evistence of branch linked polythiourethane after forming bonds of $\mathrm{SH}$ with diisocyanate. The ester group for PETMP of ophthalmic lens 9 was assigned to the shoulder peak in the region of $1739 \mathrm{~cm}^{-1}$ as shown in Figure 3.

Figure 4. 5 and 6 show thermograms of TMA for ophthalnic lenses of GMT + TDI, GMT + XDI. GST + TDI, GST + $\mathrm{XDI}, 3,4,5,6,7,8,9$ and 10 , respectively. Thermal distortion starting temperatures in TMA thermograns of GMT + TDI, GST + TDI, 3 and 7 are high considerably in comparison with $\mathrm{GMT}+\mathrm{XDI}$. GST $+\mathrm{XDI}, \mathbf{4}$ and $\mathbf{8}$. It can be estimated as the cross-linking difference by a steric effect between benzene group and benzyl group of polythiourethane made from polythiol with TDI and XDI.

Thermal resistance of ophthalmic lenses shows as order of $\mathrm{GMT}+\mathrm{TDI}>\mathrm{GST}+\mathrm{TDI}>\mathrm{GMT}+\mathrm{XDI}>\mathrm{GST}+\mathrm{XDI}>\mathbf{3}>$ $5>7>9>6>10>4>8$ as shown in Figure 4.5 and 6 . They have a low thermal distortion temperature and thermal resistance of ophthalmic lens due to flexible long alkyl chains and low cross-linking density in comparison with GMT and GST as listed in Table 1 . Thermal resistance and thermal distortion starting temperature of polythiol materials is in the order of GMT > GST > GMTT > GSTT. Diisocyanates in ophthalmic lenses have an influence on themal resistance as order of TDI $>$ IPDI $>$ XDI. The thermal properties of ophthalmic lenses were affected largely by not only thiol materials by but also diisocyanate materials. In particular. ophthalmic lens made using TDI has the lighest thermal resistance in comparison with $\mathrm{XDI}$ and IPDI as listed in Table 1 . It may be affected by $\pi \cdot \pi$ stacking for aromatic ring of TDI and its regular arrangements.

Impact strength of ophthalmic lenses made by thiol ma-

Table 1. Thennal distortion starting temperature of ophthalmic lenses prepared by thiol and disocyanate materials as urethane materials.

\begin{tabular}{lccc}
\hline Number & $\begin{array}{c}\text { Thiol and } \\
\text { disocyanate } \\
\text { materials }\end{array}$ & $\begin{array}{c}\text { Refractive } \\
\text { index }(\text { nd) } \\
\text { at } 20^{\circ} \mathrm{C}\end{array}$ & $\begin{array}{c}\text { Thermal distortion } \\
\text { starting tem- } \\
\text { perature (Ts, "C) }\end{array}$ \\
\hline No.1 & GMT + TDI & 1.6583 & 143.00 \\
No.2 & GMT + XDI & 1.6582 & 95.86 \\
No.3 & GMT + IPDI & 1.5838 & 116.10 \\
No.4 & GST + TDI & 1.6589 & 122.65 \\
No.5 & GST + XDI & 1.6589 & 76.19 \\
No.6 & GST + IPDI & 1.5960 & 112.83 \\
No.7 & $\mathbf{3}$ & 1.6591 & 86.39 \\
No.8 & 4 & 1.6590 & 48.71 \\
No.9 & $\mathbf{5}$ & 1.6585 & 83.32 \\
No.10 & 6 & 1.6041 & 52.47 \\
No.11 & 7 & 1.6586 & 68.92 \\
No.12 & $\mathbf{8}$ & 1.6588 & 40.65 \\
No.13 & 9 & 1.6581 & 67.67 \\
No.14 & $\mathbf{1 0}$ & 1.5940 & 50.66 \\
\hline
\end{tabular}


Table 2. Test of impact strength of ophthalnic lenses prepared by thiol and dissocyanate materials as urethane materials.

\begin{tabular}{ccccc}
\hline \multirow{2}{*}{ Number } & $\begin{array}{c}\text { Thiol and } \\
\text { diisocyanate } \\
\text { mnaterials }\end{array}$ & \multicolumn{3}{c}{$\begin{array}{c}\text { Impact strength for optical lens } \\
\text { thickness }\end{array}$} \\
\cline { 3 - 5 } No.1 & GMT + TDI & Fail & Fail & Fail \\
No.2 & GMT + XDI & Fail & Fail & Fail \\
No.3 & GMT + IPDI & Fail & Fail & Fail \\
No.4 & GST + TDI & Fail & Fail & Fail \\
No.5 & GST + XDI & Pass & Pass & Pass \\
No.6 & GST + IPDI & Fail & Fail & Fail \\
No.7 & $\mathbf{3}$ & Fail & Fail & Fail \\
No.8 & 4 & Pass & Pass & Pass \\
No.9 & $\mathbf{5}$ & Pass & Pass & Pass \\
No.10 & $\mathbf{6}$ & Pass & Pass & Pass \\
No.11 & $\mathbf{7}$ & Pass & Pass & Pass \\
No.12 & $\mathbf{8}$ & Pass & Pass & Pass \\
No.13 & 9 & Pass & Pass & Pass \\
No.14 & $\mathbf{1 0}$ & Pass & Pass & Pass \\
\hline
\end{tabular}

terials showed as the order of $\mathbf{2}>\mathbf{1}>$ GST $>$ GMT as listed in Table 2. Impact strength of non-coated ophthalmic lens made using thiol materials with XDI has passed the drop ball test of $95.1155 \mathrm{~g}$ from a height of $170 \mathrm{~cm}$ except GMT as shown in Table 2 .

Impact strength of FDA for ophthalmic lens should be passed the drop ball test of $16 \mathrm{~g}$ from a height of $127 \mathrm{~cm}$ and it is to be remained an intact lens after drop ball test. Non-coated ophthalmic lenses made using GST, 1 and 2 have passed the drop ball test of $68 \mathrm{~g}$ from a height of $127 \mathrm{~cm}$. but that made using GMT has not even passed the drop ball test of $32 \mathrm{~g}$ from a height of $127 \mathrm{~cm}$. Even through ophthalmic lenses made using GMT and GST have a high themal resistance. they have problems for impact strength. Here, if impact strength was increased. thermal resistance was decreased. It showed inversely between thermal resistance and impact strength each other.

Ophthalmic lenses of 5. 6. 9. and 10 for improved methods using 1 and 2 as shown in Figure 6 have produced better ophthalmic lenses than those of 3.4.7 and 8 . In order to obtain excellent ophthalmic lenses via improved mixed ratios having excellent physical properties and optical properties. further studies for lens process test are being investigated.

In summary. novel thiol materials for plastic optical lens have been synthesized and their stnictures identified by EA. EI-MS, FT-IR. ${ }^{1} \mathrm{H}$ and ${ }^{13} \mathrm{C}$ NMR spectroscopies. Their mechanisms have been studied via their synthetic route and polythiol materials in this work were only produced from polyalcohol compounds bearing 2-mercaptoethanol units. The thermal sta- bility of thiol materials showed as the order of GMT $<$ GST $<$ $\mathbf{2}<\mathbf{1}$ by TGA. Thermal resistance of ophthalmic lens showed as the order of GMT $>$ GST $>\mathbf{1}>\mathbf{2}$ by TMA data. Thermal resistance of ophthalnic lens was affected largely by not only thiol materials but also diisocyanates compounds. Diisocyanates have an influence on the therntal resistance as order of TDI $>$ IPDI $>$ XDI, while polythiol materials were shown as the order of GMT $>$ GST $>1>2$. Impact strength of non-coated ophthalnic lenses made using thiol materials with XDI have passed the drop ball test of $95 \mathrm{~g}$ from the height of $170 \mathrm{~cm}$ except GMT. If the impact strength of lenses under the same conditions was increased, its thermal resistance was decreased. It contrasts thermal resistance with impact strength. Ophthalmic lenses 5 and 6 made by improved mixed ratios using 1 and 2 were prepared better ophthalmic lenses than 3 and 4 . In order to obtain excellent ophthalmic lenses. further studies for lens process are being investigated. It is possible of utility for the industrialization due to colorless. transparency and good physical and optical properties.

Aclonowledgments. This research work was supported by Hannam University Research Fund (2009).

\section{Refeiences}

1. Kanemura, Y.: Imai, M.: Sasagawa, K,: Kagimoto, N.: Nagata, T. Korea Patent 1987-0001768, 1987.

2. Okazaki, M.: Kuma, S.: Kanemura, Y. Japan Patent 2001039944. 2001 .

3. Kawanchi, K.: Sasagawa, K.: Kobayashi, S. Japan Patent JP8157446. 1996.

4. Morishiri, H.; Kobayashi, S. Japan Patent 2006001982, 2006.

5. Kanemura, Y.: Sasagawa, K.: Imai, M: Suzuki, T. Korean Patent 10-0055948, 1992

6. Morishir, H.; Kobayashi, S. Japan Patent 2005350531, 2005.

7. Okubo, T.: Honma, M.: Wang, M.: Takamatsu, T. Japan Patent 2004310001.2004 .

8. Kanemura, Y.: Sasagawa, K.; Kobayashi, S. European Patent $0528590 \mathrm{Al}, 1992$.

9. Vụjasinovi, I.; Veljovi, I.; Minari-Mạjerski, K. J. Org. Chem. $2004,69(24), 8550$

10. Szonyi, F.: Cambon, A. J. Fhom Chem 1987, $36(2), 195$

11. Wolf, R. E.: Hartman, J. I. R.; Storey, I. M. E.; Foxman, B. M.; Cooper, S. R. J.Am. Chem. Soc. 1987, 109(14), 4328

12. Zeng, L.; Miller, E. W.; Pralle, A.: Isacoff, E. Y.; Chang, C. I. J. Am. Chem. Soc. 2006, 128(1), 10

13. Buter, J.: Kellogg, R. M. Onganic Sintheses 1987, 65, 150.

14. Guyon, V.; Guy, A.; Foos, J.; Lemaire, M.; Draye, M. Tetrohedron $1995,5 I(14), 4065$.

15. Jang, D. G.; Kim, J. H.; Lee, S. M; Roh, S. G. J. Korean Oph. Opt. Soc. $2008,13(3), 1$.

16. Okazaki, K, Kanemura, Y.; Nagata, T. Kowe Patent 10-0180926, 1998. 